\title{
Exergy Analysis of Combined Heat and Power (CHP) Plants
}

\author{
Jairo Rúa Lars O. Nord \\ Department of Energy and Process Engineering, NTNU - Norwegian University of Science and Technology, \\ Trondheim - Norway, jairo.r.pazos@ntnu.no
}

\begin{abstract}
Combined heat and power plants are an efficient technology for waste heat recovery applications where both heat and power are demanded. Steam Rankine cycles are normally utilized when high temperature exhaust streams are available. Different heat demands and temperatures might be expected depending on the application. Thus, designing a power system capable of meeting the heat demand and producing the maximum possible power supposes a challenge. This work aims at providing some guidelines to properly select, from a second law perspective, a CHP plant configuration depending on the heat demand and temperature. Two plant configurations are considered and broad ranges of heat demand and temperature are studied. A software developed in MATLAB was utilized for all thermodynamic property calculations. Optimization of the thermodynamic cycle was carried out for each set of conditions and the best possible scenario was always evaluated. An exergy analysis of the components integrating the power plant was then performed, pointing out where irreversibilities were more predominant and where there was more potential for improvements. Results showed that extracting process heat in the condenser was more beneficial than utilizing a supplementary heat exchanger in series with the heat recovery steam generator.

Keywords: steam Rankine cycle, waste heat recovery, gradient-based optimization, Second law analysis.
\end{abstract}

\section{Introduction}

Uncontrolled and prolonged emissions of anthropogenic greenhouse gases (GHG) have increased by $40 \%$ the atmospheric concentrations of $\mathrm{CO}_{2}$ with respect to preindustrial levels. Combustion of fossil fuels is the main source of these anthropogenic GHG emissions, which accounts for $78 \%$ of the total emission increase in the period from 1970 to 2010. Accordingly, there is a scientific consensus that this irresponsible human behaviour is one of the major drivers of global warming and climate change (IPCC, 2014). However, power generation and industry are expected to rely on fossil fuel combustion until the end of the century (IEA, 2016). Efficiency improvement is considered a promising mitigation alternative that aims at reducing the $\mathrm{CO}_{2}$ emissions on these sectors (IEA, 2016).

Waste heat recovery from both power generation systems and energy intensive industries is expected to lead to higher efficiencies and lower $\mathrm{CO}_{2}$ emissions (Nord and
Bolland, 2013; Quoilin et al., 2013). Combined heat and power (CHP) plants are suitable alternatives for waste heat applications where there is a demand of both heat and power. Nevertheless, the design of these systems is a major challenge due to the broad range of exhaust gas temperatures and the different heat demand and temperature.

Exergy analysis accounts for the irreversibilities that take place in each component of the cycle and leads to designs where maximum use of the available exergy is achieved. Many studies analyse complex systems in order to identify such irreversibilities. However, some of them do not motivate, economically or thermodynamically, the selection of a specific plant configuration. From an engineering perspective, both adequate thermodynamic performance and plant structure are fundamental choices that determine the efficient operation of a power or CHP plant. Consequently, it is not possible to ensure peak performance of any power system if only one of these two factors is motivated. Ertesvåg (2007) defined a parameter to compare the exergy improvements that are achieved using a CHP plant with the separate production of heat and power. Results showed that industrial CHP plants with gas turbines, bypass in the condenser for heat production, and back-pressure steam turbines are beneficial from a exergy perspective. Wang et al. (2009) carried out an exergy optimization and analysis of different types of cycles and configurations for waste heat recovery in a cement plant. They concluded the Kalina cycle leads to the highest efficiency, although the simple flash steam cycle leads to good performance with a simpler cycle configuration. Ahmadi and Dincer (2010) performed an exergo-economic analysis of an existing CHP plant where heat demand and temperature were defined. The effect of power demand and fuel cost on different parameters of the cycle was studied through a sensitivity analysis. It was found that economic saving may be achieved if the suitable turbomachinery and an adequate CHP plant design are selected according to a expected power demand.

This work aims at providing some guidelines for the selection of optimal CHP plant configurations for waste heat recovery applications at high temperature. In Section 2 two different CHP plants for producing a wide range of temperature and heat demands are described, the exergy analysis methodology is presented, and the optimization procedure for maximizing the power output is detailed. Results for both CHP plant configurations are shown and compared in Section 3. 


\section{Analytical Procedure}

\subsection{Case Study}

The case study analysed in this work is a combined cycle where a flow of exhaust gas at $550{ }^{\circ} \mathrm{C}$ is utilized to produce the steam that drives the turbine in a simple Rankine cycle and the process heat required. Water is selected as working fluid due to the high temperature of the hot fluid (Hung et al., 1997). Waste heat recovery applications, such as those on offshore platforms or ships are normally subjected to weight and space limitations. Therefore, a single pressure once-through steam generator is utilized as a trade-off between compactness and heat exchange efficiency (Nord and Bolland, 2012, 2013). Two different configurations, whose layouts are shown respectively in Figure 1 and Figure 2, are studied:

1. Process heat is generated in the condenser with the heat rejected by the steam during its condensing before being pumped to restart the cycle. In this scenario, a back-pressure steam turbine may be utilized in order to leave some energy in the steam that enables the production of the demanded amount of heat at the required temperature. As process heat is produced in the condenser, the exhaust flow is entirely utilized to generate the maximum amount of steam for a certain temperature at the inlet of the turbine.

2. A supplementary heat exchanger is installed after the heat recovery steam generator (HRSG) to produce the required process heat. Therefore, it is not possible to employ all the exhaust gas energy for the generation of steam as there must be some available for the production of process heat. However, in this case, the generation of power is not limited by the backpressure of the steam turbine as no useful energy is going to be obtained from the condenser. Maximum possible expansion is hence occurring in the steam turbine.

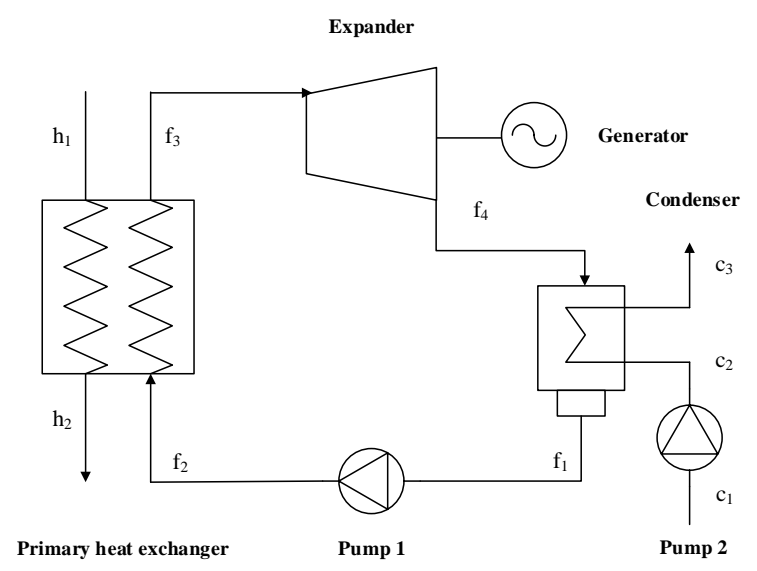

Figure 1. Simple Rankine cycle layout with heat extraction in the condenser.
Table 1. Specification assumed for the case study.

\begin{tabular}{lcc}
\hline Variable & Nomenclature & Value \\
\hline Ambient Temperature & $T_{0}$ & $10^{\circ} \mathrm{C}$ \\
Ambient Pressure & $p_{0}$ & $1 \mathrm{~atm}$ \\
Heat Source Temperature & $T_{h_{1}}$ & $550{ }^{\circ} \mathrm{C}$ \\
Heat Source Mass Flow Rate & $\dot{m}_{h}$ & $80 \mathrm{~kg} / \mathrm{s}$ \\
Heat Source Outlet Pressure & $p_{h_{2}}$ or $p_{h_{3}}$ & $1 \mathrm{~atm}$ \\
Process Heat Fluid Temperature & $T_{c_{1}}$ or $T_{p_{1}}$ & $25^{\circ} \mathrm{C}$ \\
Process Heat Fluid Outlet Pressure & $p_{c_{3}}$ or $p_{p_{2}}$ & $2.5 \mathrm{~atm}$ \\
Process Heat Fluid Inlet Pressure & $p_{c_{1}}$ or $p_{p_{1}}$ & $1.5 \mathrm{~atm}$ \\
Cooling Fluid Temperature & $T_{c_{1}}$ & $10^{\circ} \mathrm{C}$ \\
& & \\
& $\mathrm{CO}_{2}$ & $5.23 \mathrm{~mol}-\%$ \\
Heat Source Composition & $\mathrm{H}_{2} \mathrm{O}$ & $4.29 \mathrm{~mol}-\%$ \\
& $\mathrm{O}_{2}$ & $15.24 \mathrm{~mol}-\%$ \\
& $\mathrm{~N}_{2}$ & $75.24 \mathrm{~mol}-\%$ \\
\hline
\end{tabular}

Almost all exhaust gases originated from the combustion of fossil fuels contain sulphurs that may condensate and cause corrosion when the temperature is excessively low. Thus, in practice, a minimum temperature at the outlet of the heat exchanger is fixed in order to avoid such problems. In this case, a "clean" gas stream was assumed. Limitations related to practical operation issues were not considered and hence a exhaust gas low temperature limit of $40^{\circ} \mathrm{C}$ was used. Pressurized water at 2.5 bar was utilized as both fluid media in the process heat generation and as cooling fluid in the condenser for configuration 2 . Process heat demand and temperature were varied during this study so the effect of these variables on the exergy utilization and efficiency may be observed. A summary of the specifications assumed in this work is in Table 1.

\subsection{Exergy Analysis}

Steady-state mass and energy conservation laws are implemented in every component so the inlet and outlet states of every component may be calculated. The REFPROP library (Lemmon et al., 2013) is utilized to determine the required thermodynamic variables in every state

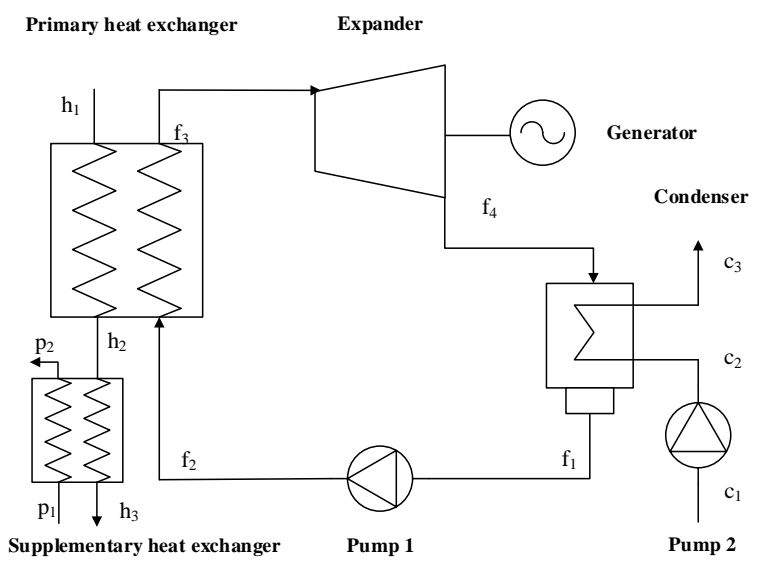

Figure 2. Simple Rankine cycle with supplementary heat exchanger layout. 
(IAPWS formulation for the thermodynamic properties of water and steam). Once the thermodynamic states that specify the components' operation are known, exergy calculations can be performed. Exergy content is calculated in every state and thus, by means of exergy balances, the exergy transfer and destruction that occurs in the components integrating the cycle are calculated. More details about the implementation of this procedure in MATLAB can be found in the work done by Agromayor and Nord (2017).

Thermo-mechanical exergy was exclusively considered. When exergy balances are considered for every component, the chemical exergy between two different states cancels out. Point $h_{1}$ is the only state where it could be considered, being included in the exergy losses associated to the exhaust gas that is released to the atmosphere and thus reducing the second law efficiency of the plant. However, special ideal membranes that allow the individual expansion of the components integrating the exhaust gas stream would be needed (Kotas, 2012). This is unrealistic for a power plant and therefore chemical exergy is not utilized in the proposed case. In addition, kinetic and potential energies, and its contribution in the exergy calculations, were neglected.

\subsection{Optimization}

Second law plant efficiency, defined in Eq. 1, was selected as the objective function to be maximized in the Rankine cycle optimization. The numerator represents the net exergy extracted from the turbine in the process, which accounts for the net power produced in the bottoming cycle. Process heat, i.e. the thermo-mechanical exergy contained in the process heat stream $\left(\dot{E}_{c_{3}}\right.$ for configuration 1 and $\dot{E}_{p_{2}}$ for configuration 2), is considered as a constraint in the optimization problem since power plant operators normally prefer to produce electricity rather than heat. The denominator is the thermo-mechanical exergy contained by the heat source at the inlet of the primary heat exchanger, $\dot{E}_{h_{1}}$. Selecting this parameter as denominator allows to know how well the exergy content of the hot stream is utilized for the desired purposes, which is one of the main objectives of a waste heat recovery application.

$$
\eta_{\text {II,plant }}=\frac{\dot{W}_{\text {net }}}{\dot{E}_{h_{1}}}
$$

Net power is defined in Eq. 2 as the difference between the power produced by the steam turbine and the power consumed by the pumps. Process heat exergy, $\dot{E}_{\text {heat }}$, accounts for the work that could be obtained if the fluid was taken reversibly to restricted equilibrium (Kotas, 2012) (see Eq. 3).

$$
\begin{gathered}
\dot{W}_{\text {net }}=\left|\dot{W}_{\text {turb }}\right|-\left|\dot{W}_{\text {pump }_{\text {cycle }}}\right|-\left|\dot{W}_{\text {pump }_{c}}\right|-\left|\dot{W}_{\text {pump }_{\text {sup }}}\right| \\
\dot{E}_{\text {heat }}=\dot{m}_{\text {heat }} e_{\text {heat }}=\dot{m}_{\text {heat }}\left[\left(h-h_{0}\right)-T_{0}\left(s-s_{0}\right)\right]
\end{gathered}
$$

During the optimization many variables are kept constant. A summary of the values of these variables is presented in Table. 2.
Table 2. Fixed variables during the Rankine cycle optimization.

\begin{tabular}{lcc}
\hline Variable & Nomenclature & Value \\
\hline HRSG Pressure Drop Heat Source Side & $\Delta p_{h_{H R S G}}[\%]$ & 2 \\
HRSG Pressure Drop Working Fluid Side & $\Delta p_{w_{H R S G}}[\%]$ & 2 \\
Condenser Pressure Drop Cooling Fluid Side & $\Delta p_{c}[\%]$ & 2 \\
Condenser Pressure Drop Working Fluid Side & $\Delta p_{w_{\text {cond }}}[\%]$ & 1 \\
Supplementary HE Pressure Drop Working Fluid Side & $\Delta p_{w_{\text {sup }}}[\%]$ & 1 \\
Supplementary HE Pressure Drop Heat Source Side & $\Delta p_{h_{\text {sup }}}[\%]$ & 1 \\
Expander Polytropic Efficiency & $\eta_{\text {turb }}[\%]$ & 80 \\
Pump Polytropic Efficiency & $\eta_{\text {pump }}[\%]$ & 70 \\
HRSG Minimum Temperature Difference & $\Delta T_{\min , H R S G}\left[{ }^{\circ} \mathrm{C}\right]$ & 10 \\
Condenser Minimum Temperature Difference & $\Delta T_{\min , c}\left[{ }^{\circ} \mathrm{C}\right]$ & 10 \\
\hline
\end{tabular}

In the model employed in this work, five degrees of freedom are enough to sequentially calculate all the thermodynamic states without solving any system of algebraic equations. These degrees of freedom are:

1. Outlet temperature of the heat source.

2. Pressure at the inlet of the turbine.

3. Pressure at the outlet of the turbine.

4. Enthalpy at the inlet of the turbine.

5. Enthalpy at the inlet of the HRSG.

\section{Results and Discussion}

Simulations for process heat demand varying between 30 and $42 \mathrm{MW}$, and temperature requirements ranging from 50 to $90{ }^{\circ} \mathrm{C}$ were performed. The temperature interval was selected based on a low quality heat demand where the produced heat will be used for low temperature applications. The choice of the process heat demand range was based on an optimization of the cycle without any constraint on the heat demand and an outlet temperature of $50{ }^{\circ} \mathrm{C}$ at the outlet of the condenser. It was observed that the heat flow rate in the condenser was $25 \mathrm{MW}$ and hence higher values had to be tested. An upper limit to the maximum process heat that could be produced was found close to $44 \mathrm{MW}$, where the cycle needed to consume power instead of producing it, i.e. a negative second law efficiency was obtained. The selected range was $30-42 \mathrm{MW}$ in order to ensure that sufficient heat (limited by the lower bound) and power (limited by the upper bound) were produced in all cases.

\subsection{Simple Rankine Cycle}

Second law efficiency variation with heat demand and temperature may be observed in Figure 3. As it could be expected, increasing temperature and heat demand have a negative effect on the second law efficiency. From Figure 4 can be observed that two opposite tendencies are found in the cycle. Irreversibility becomes larger in the HRSG and the condenser as the heat demand increases, but less exergy is destructed in the turbine and the pump (not shown due to small scale) when the demand of heat is 


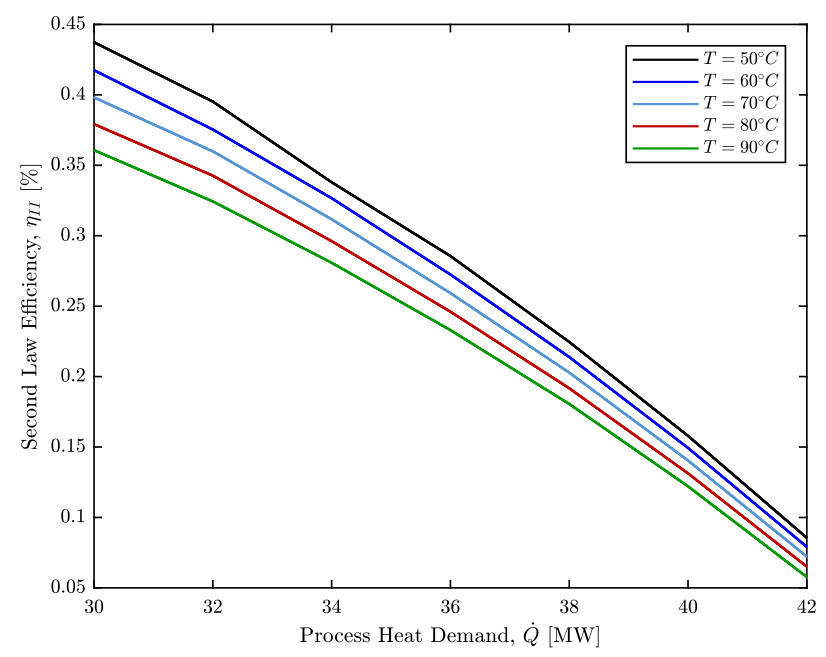

Figure 3. Second law efficiencies for simple Rankine cycle.

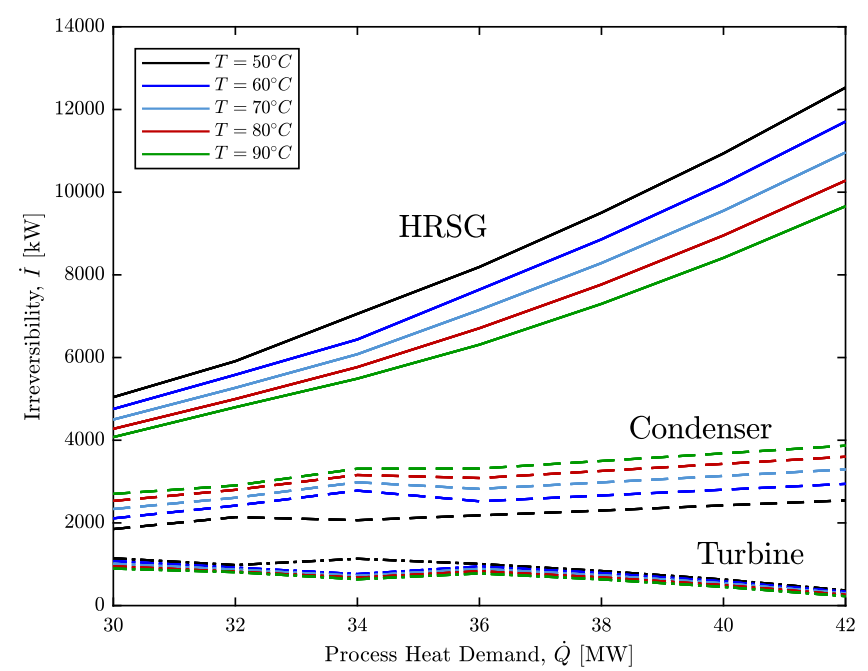

Figure 4. Irreversibility variation of the components of the simple Rankine cycle.

raised. The increase of both heat exchanger's irreversibility with the heat demand outweighs the reduction in exergy destruction that occurs in the turbomachinery and hence the overall effect of the heat demand on the second law efficiency is negative, i.e. it is reduced as the heat demand raises.

Mathematically, the connection between the reduction in the turbine's irreversibility with the increase in the process heat can be proven. Combining the polytropic efficiency of the turbine $\eta_{p}$ shown in Eq. 4, and Eq. 5, where subscript $s$ stands for isentropic,

$$
\begin{gathered}
\eta_{p}=\frac{\mathrm{d} h}{\mathrm{~d} h_{s}} \\
T \mathrm{~d} s=\mathrm{d} h-v \mathrm{~d} p \quad \text { and } \mathrm{d} h_{s}=v \mathrm{~d} p
\end{gathered}
$$

the following expression is obtained:

$$
\eta_{p}=\frac{T \mathrm{~d} s+v \mathrm{~d} p}{v \mathrm{~d} p}=1+\frac{T \mathrm{~d} s}{v \mathrm{~d} p}
$$

If ideal gas behaviour of the steam is assumed (only for qualitative analysis purposes), Eq. 6 becomes:

$$
d s=R\left(\eta_{p}-1\right) \frac{\mathrm{d} p}{p}
$$

Integrating between the inlet and the outlet of the turbine:

$$
\Delta s=R\left(1-\eta_{p}\right) \ln \left(\frac{p_{3}}{p_{4}}\right)
$$

It is possible to observe that entropy increment, and hence irreversibility (see Eq. 8), depend on the pressure ratio in the turbine and the polytropic efficiency. Since the polytropic efficiency is considered constant, the exergy destruction in the turbine only depends on the pressure ratio. From Figure 5 it can be seen that the pressure ratio decreases with increasing heat demand. Therefore, it is shown that the irreversibility in this case decreases with higher heat requirements.

In the pump's case the ratio between the specific volume and temperature in Eq. 6 is constant, and hence the following expression is obtained:

$$
\Delta s=K\left(1-\eta_{p}\right)\left(p_{2}-p_{1}\right)
$$

with $\mathrm{K}$ being a constant that represents the ratio between the specific volume and temperature, where the former is constant because water is an incompressible fluid and the variation in the latter is neglected since it is small. Thus, it is shown that, as it occurred in the turbine, the irreversibility in the pump decreases as the process heat demand increases.

From a second law analysis of a heat transfer process between a hot and a cold stream it can be shown that the entropy generation $\dot{\sigma}$, and thus the irreversibility, are proportional to the temperature difference and the heat exchanged. This can be proven assuming a heat exchange process between constant hot and cold flows without friction. The control volume is set so the heat transfer process occurs at $T_{H}$, and all the entropy generation is included. For the cold fluid, the first and second law, and the T-s equations are, respectively:

$$
\begin{gathered}
0=\delta \dot{Q}+\dot{m}_{C} \mathrm{~d} h_{C} \\
0=\frac{\delta \dot{Q}}{T_{H}}+\dot{m}_{C} \mathrm{~d} s_{C}+\delta \dot{\sigma} \\
T_{C} \mathrm{~d} s_{C}=\mathrm{d} h_{H}
\end{gathered}
$$

Combining these three equations the following expression showing the relation between the entropy production and the existence of a finite temperature difference is obtained:

$$
\delta \dot{\sigma}=\frac{T_{H}-T_{C}}{T_{H} T_{C}} \delta \dot{Q}
$$




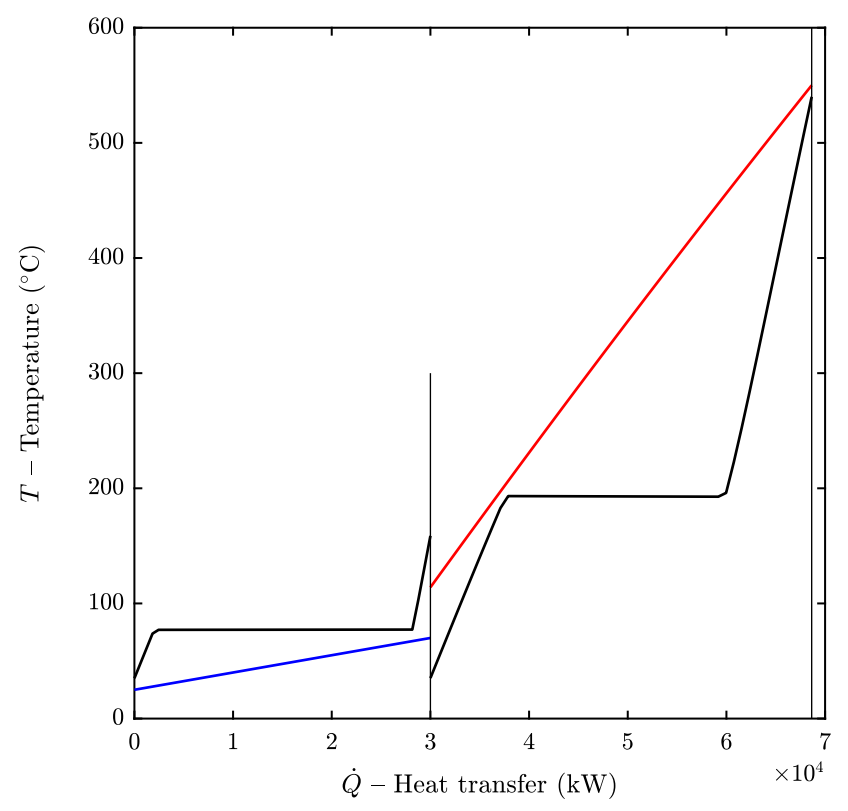

(a) $\mathrm{T}$-Q diagram for $\mathrm{T}=70^{\circ} \mathrm{C}$ and $\mathrm{Q}=30 \mathrm{MW}$.

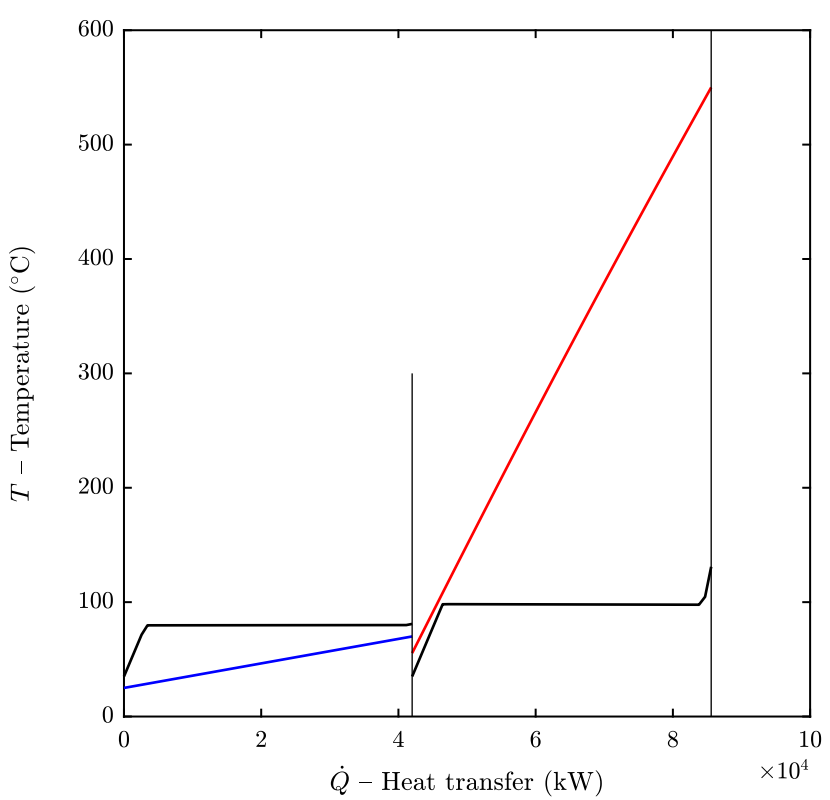

(b) $\mathrm{T}$-Q diagram for $\mathrm{T}=70^{\circ} \mathrm{C}$ and $\mathrm{Q}=42 \mathrm{MW}$.

Figure 5. Effect of process heat demand on the optimal cycle configuration for the simple Rankine cycle.

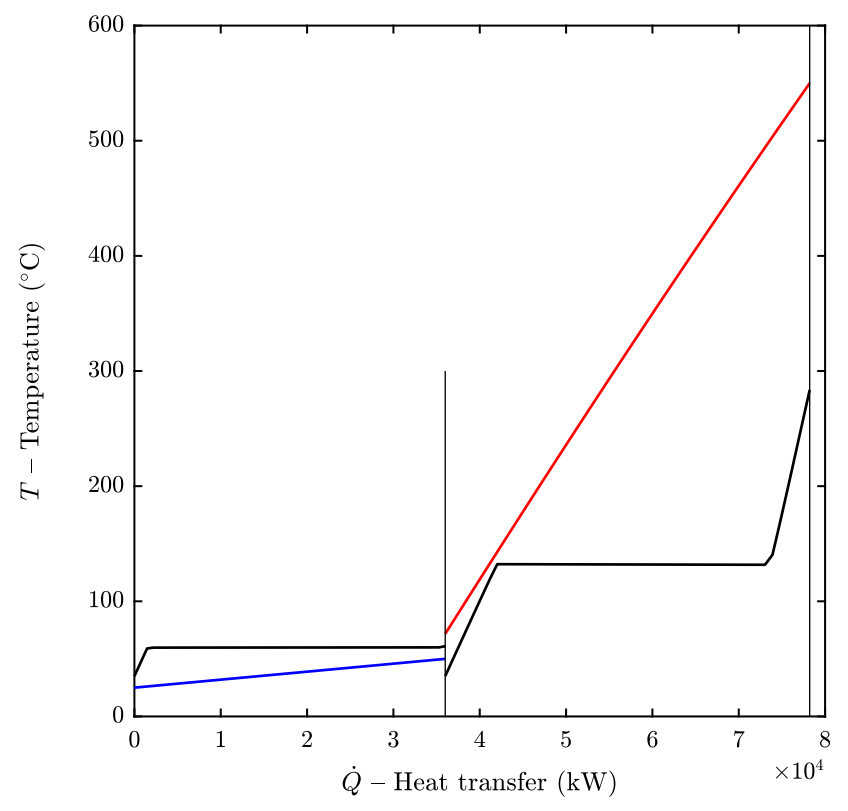

(a) $\mathrm{T}-\mathrm{Q}$ diagram for $\mathrm{T}=50^{\circ} \mathrm{C}$ and $\mathrm{Q}=36 \mathrm{MW}$.

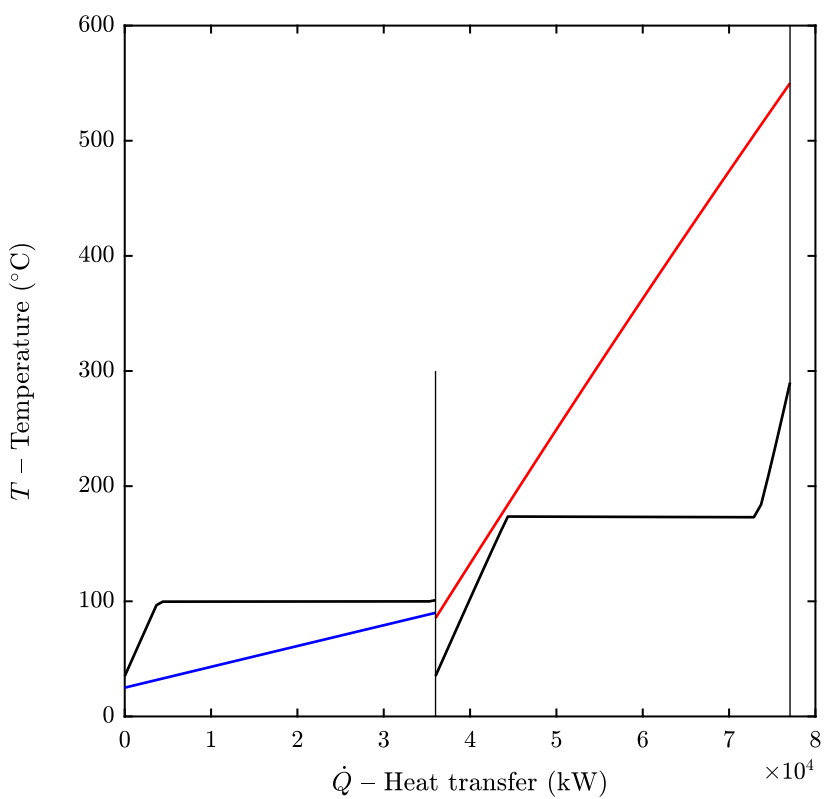

(b) $\mathrm{T}$-Q diagram for $\mathrm{T}=90^{\circ} \mathrm{C}$ and $\mathrm{Q}=36 \mathrm{MW}$.

Figure 6. Effect of process heat temperature on the optimal cycle configuration for the simple Rankine cycle.

Consequently, for the heat recovery steam generator, the heat transferred increases with the process heat demand and so does the irreversibility. In addition, high process heat demand implies less pressure ratio, which increases the temperature difference between the hot stream of exhaust gases and the pressurized working fluid along the HRSG, leading to higher entropy generation. Lastly, smaller pressure ratios mean that the overall cold stream temperature in the heat recovery steam generator is reduced, and hence the denominator in Eq. 13 is smaller for larger process heat demands.
The irreversibility in the condenser is also increased with the process heat demand because the heat transferred is larger. This effect may be observed in Figure 4, where there is a linear tendency for the condenser irreversibility lines. Different back-pressures at the outlet of the turbine originated by different process heat demands may lead to different hot temperatures along the condenser, which would imply different temperature differences and modifications in the denominator's product. However, these changes balance each other and the linear tendency due to the heat transferred dominates the exergy destruction. 
Temperature influence in the second law efficiency of the power plant can also be understood if irreversibility in each component is analysed. High temperatures lead to smaller pressure ratios in the cycle for a given process heat demand (see Figure 6). Therefore, the irreversibility in the turbine and the pump decreases as the required temperature increases (see Eq. 8 and Eq. 9, respectively).

The effect of temperature in the heat recovery steam generator and the condenser can be clearly observed in Figure 4. The temperature in the process heat stream has a strong effect in the high and low pressures of the cycle. These pressures influence the temperature difference between the hot and cold streams in each heat exchanger and hence affect the exergy destruction taking place in both components.

In case of the heat recovery steam generator, the high pressure increase associated to the raise in the temperature of the process heat stream leads to a reduction of the irreversibility. Larger high pressures imply higher saturation temperature and hence the overall temperature difference along the component decreases, leading to smaller exergy destruction. The saturation temperature increase in the heat recovery steam generator also indicates larger overall cold temperature along the component, which enhances the reduction in entropy generation (see Eq. 13).

High temperatures in the outlet of the cold stream of the condenser lead to larger temperature differences along the component. This effect outbalances the increase of the denominator product associated to the increase of the overall temperature of the cooling fluid. Therefore, the entropy generation is boosted by the increase in the temperature requirements for the process heat stream.

From this analysis, it could be thought that the temperature raise of the process heat stream could lead to an improvement of the second law efficiency as the irreversibility of the heat recovery steam generator, the component with larger effect on this parameter, decreases for higher temperatures. However, in addition to an exergy destruction analysis, it is important to take into account the utilization of the exhaust gas stream and the power produced in the turbine. Exergy flow to the cycle and power generation in the turbine decrease as the temperature is increased. Thus, albeit the smaller irreversibility in the HRSG, high temperature requirements in the heat stream lead to lower values of the second law efficiency because a larger fraction of exergy leaves with the exhaust gases without being recovered by the cycle. The exergy content of the exhaust gases is simply destroyed in the ambient without being utilized.

\subsection{Rankine Cycle with Supplementary Heat Exchanger}

Second law efficiency variation with process heat demand and temperature are shown in Figure 7. Similarly to what occurred with the simple Rankine cycle configuration, second law efficiency decreases as the process heat demand is raised. However, temperature has no effect on this

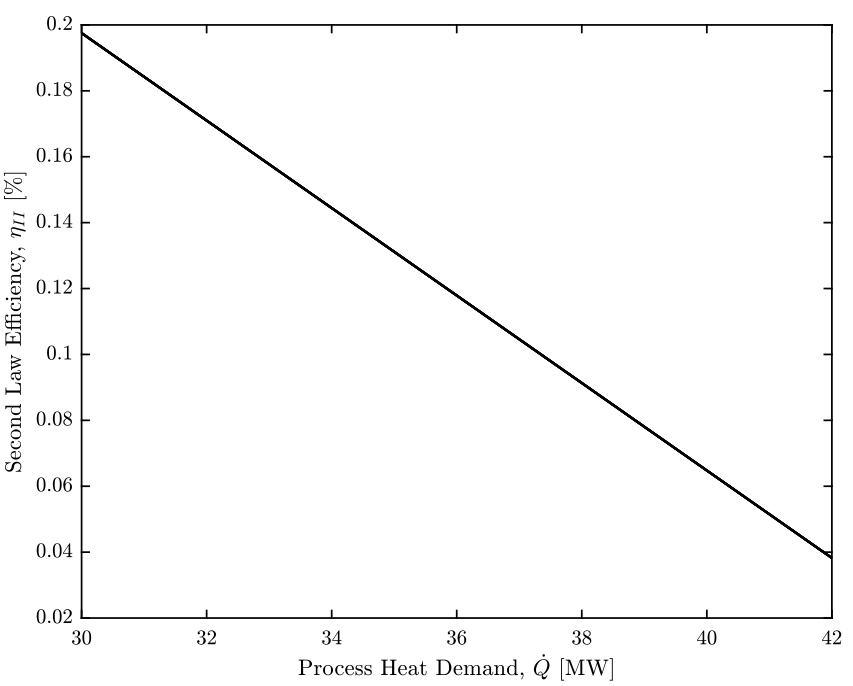

Figure 7. Second law efficiency variation of the Rankine cycle with Supplementary HE.

parameter as it can be clearly observed. In addition, and as it could be expected from the non-variation of the second law efficiency with process heat temperature, irreversibility in each of the cycle's components is also independent from the process heat temperature. This behaviour may be observed in Figure 8a.

Invariance of the second law efficiency with process heat temperature can be explained from an optimization perspective. Described before, during the optimization procedure, the outlet temperature required for the process heat stream is fixed while the amount of demanded heat is set as an equality constraint. When the required temperature is the lowest, i.e. $50^{\circ} \mathrm{C}$, a maximum for the efficiency is found with an associated temperature at the outlet of the HRSG of the exhaust gases close to or above $400{ }^{\circ} \mathrm{C}$. Thus, when the temperature requirements are increased, the same optimum point, which is the best possible point for the established conditions, is achieved since the energy contained in the exhaust gases at the outlet of the HRSG is enough to produce the demanded heat at higher temperatures. The obtained results lead to the same thermodynamic cycle. Consequently, as the objective function is the produced power in the turbine divided by the exergy content of the hot stream at the inlet of the HRSG (see Eq. 1), the second law efficiency does not change.

Identical thermodynamic cycles for different process heat temperatures imply that the pressure ratio in the turbine and the pressure difference in the pump do not change. Therefore, according to Eq. 8 and Eq. 9, exergy destruction in both components does not vary with the temperature of the process heat stream.

On the contrary, the irreversibility in the supplementary heat exchanger does change with the process heat temperature as it can be observed in Figure 8b. Different temperature in the process heat stream implies that, for the same hot inlet temperature in the supplementary heat exchanger, distinct temperature differences occur along the 


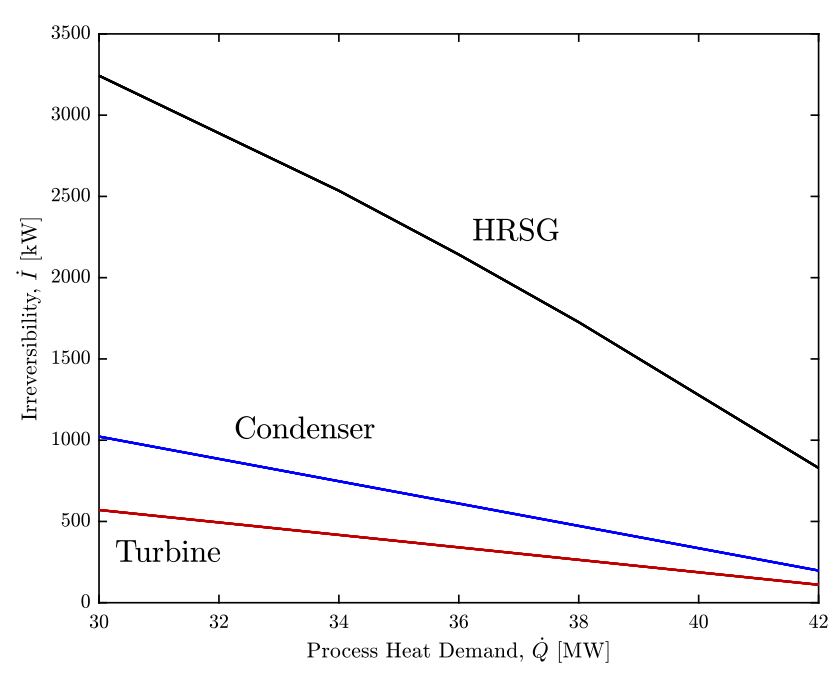

(a) Irreversibilities of HRSG, condenser and turbine.

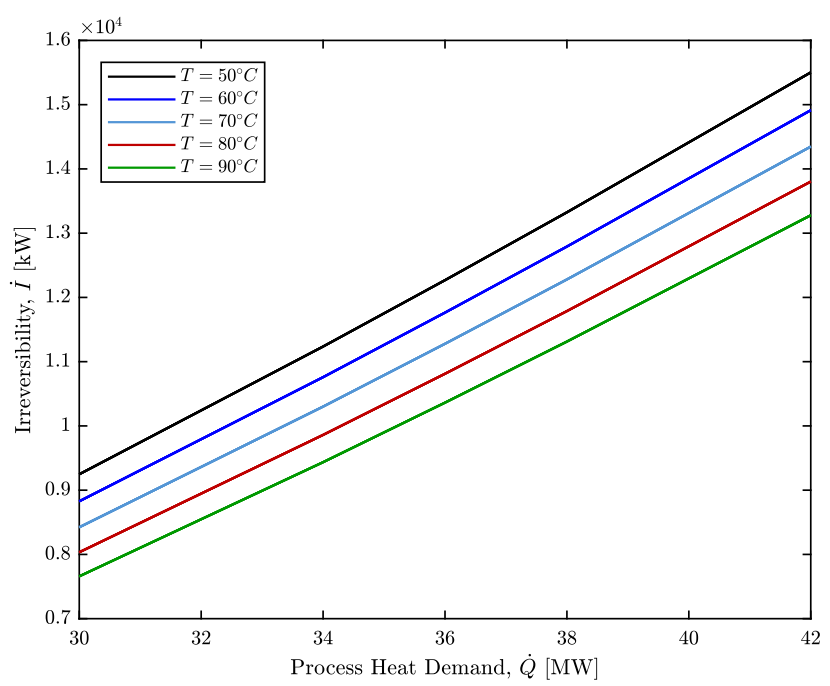

(b) Irreversibilities of supplementary heat exchanger with process heat and temperature.

Figure 8. Irreversibility variation of the components of the Rankine cycle \& supplementary HE with process heat demand and temperature.

component. Hence, the higher the process heat temperature requirements the smaller the "overall" temperature difference and the irreversibility in the component. This behaviour is explained mathematically by Eq. 13 .

Heat demand has a clear linear influence in the second law efficiency of the power plant and in the irreversibility in each component. On the contrary to what occurred for the simple Rankine cycle, exergy destruction in all $c y$ cle components decreases with the increase in the heat demand. Big changes in the high and low pressures of the cycle do not occur and hence the irreversibility is reduced as the heat demand is raised. Heat transferred in the heat recovery steam generator and the condenser decreases as the heat demand increases. Eq. 13 shows the linear relation between heat transferred and entropy generation (and consequently exergy destruction), and hence it can be understood why the irreversibility in these heat exchangers is decreased as the process heat demand increases. The "overall" hot temperature and thus the temperature difference are higher for larger heat demands, however, this effect is clearly outbalanced by the changes in the heat transfer. The weight of the heat transfer increase in the entropy generation and the linear behaviour it produces is easily observable in Figure 8.

\subsection{Configuration Comparison}

From the previous discussions in the sections above two distinguishable behaviours may be observed. The simple Rankine cycle is affected by both process heat demand and temperature since this heat is produced in the condenser and consequently affects the thermodynamic cycle directly. On the other hand, having a supplementary heat exchanger after the HRSG together with the low temperature requisites allows the second configuration to be independent of the process heat temperature. This feature could be regarded as an advantage for the second configuration but, due to the requirements imposed during the optimization, the cycle design is strongly penalized, reaching much lower efficiencies (both first and second law) than the simple Rankine configuration.

From the efficiency definitions and the results presented it can be deduced that the simple Rankine configuration produces more electric power than the configuration with supplementary heat exchanger for an equal set of process heat requirements. Larger irreversibilities are found in the components of the first cycle than in the second one for this reason, as more working fluid is circulating, more power is produced in the turbine, more power is consumed by the pump and larger temperature differences are encountered along the HRSG and the condenser. Exergy destruction is thus concentrated in the supplementary heat exchanger in the second configuration, being its magnitude almost as large as all the irreversibilities of the cycle's components in the simple Rankine cycle configuration.

\section{Conclusions}

In this work two different configurations of a combined heat and power plant were proposed for waste heat recovery applications. The first configuration produced the process heat in the condenser by utilizing a back-pressure steam turbine. In the second alternative, a supplementary heat exchanger after the heat recovery steam generator was considered. An optimization procedure of each cycle for different process heat demands and temperature was done in order to obtain the best possible design for each case. The second law efficiency was employed as the objective function and, in addition to the thermodynamic states, the irreversibility was calculated in each component. 
Both qualitative and quantitative analyses from a second law perspective were done for both power plant configurations. It was found that in both cycles the HRSG design was the main source of entropy generation due to the large heat that was transferred and the big temperature differences. However, when the second power plant configuration was analysed, the largest irreversibility occurred in the supplementary heat exchanger as a consequence of the large heat transferred and the temperature difference. Heat demand, and not process heat temperature, was the process heat parameter that had the largest effect on both efficiencies, being the variable that limits the most the power generation in the steam turbine.

The power plant with supplementary heat exchanger was independent of the process heat temperature due to the nature of the optimal solution, leading to poor efficiencies and low power production. As a consequence, the simple Rankine cycle is considered as the best of the two proposed alternatives because it does not only have better first and second law efficiencies but it is also able to generate more power for a specific process heat.

\section{References}

R. Agromayor and L. O. Nord. Fluid selection and thermodynamic optimization of organic Rankine cycles for waste heat recovery applications. Energy Procedia, 129:527-534, 2017. doi:10.1016/j.egypro.2017.09.180.

P. Ahmadi and I. Dincer. Exergoenvironmental analysis and optimization of a cogeneration plant system using Multimodal Genetic Algorithm (MGA). Energy, 35(12):51615172, 2010. doi:10.1016/j.energy.2010.07.050.

I. S. Ertesvåg. Exergetic comparison of efficiency indicators for combined heat and power (CHP). Energy, 32(11):2038-2050, 2007. doi:10.1016/j.energy.2007.05.005.

T. C. Hung, T. Y. Shai, and S. K. Wang. A Review of Organic Rankine Cycles (ORC) for the Recovery of Low-Grade Waste Heat. Energy, 22(7):661-667, 1997. doi:10.1016/j.energy.2010.07.050.

IEA. World Energy Outlook 2016. , OECD/IEA, Paris, France, 2016.

IPCC. Climate Change 2014: Synthesis Report. Contribution of Working Groups I, II and III to the Fifth Assessment Report of the Intergovernmental Panel on Climate Change [Core Writing Team, R.K. Pachauri and L.A. Meyer (eds.)], IPCC, Geneva, Switzerland, 2014.

T. J. Kotas. The Exergy Method of thermal Plant Analysis. Exergon Publishing Company UK Ltd, 2012. ISBN 978-1908341-89-1.

E. W. Lemmon, M. L. Huber, and M. O. McLinden. NIST Standard Reference Database 23: Reference Fluid Thermodynamic and Transport Properties-REFPROP, Version 9.1, National Institute of Standards and Technology, 2013.

L. O. Nord and O. Bolland. Steam bottoming cycles offshore Challenges and possibilities. Journal of Power Technologies, 92(3):201-207, 2012. doi:10.1016/j.energy.2010.07.050.
L. O. Nord and O. Bolland. Design and off-design simulations of combined cycles for offshore oil and gas installations. Applied Thermal Engineering, 54(1):85-91, 2013. doi:10.1016/j.applthermaleng.2013.01.022.

S. Quoilin, M. Van Den Broek, S. Declaye, P. Dewallef, and V. Lemort. Techno-economic survey of Organic Rankine Cycle (ORC) systems. Renewable and Sustainable Energy Reviews, 22:168-186, 2013. doi:10.1016/j.rser.2013.01.028.

J. Wang, Y. Dai, and L. Gao. Exergy analyses and parametric optimizations for different cogeneration power plants in cement industry. Applied Energy, 86(6):941-948, 2009. doi:10.1016/j.apenergy.2008.09.001. 